\title{
Causa do aquecimento global: antropogênica versus natural ${ }^{*}$
}

\author{
Robson Willians da Costa Silva \\ Universidade Estadual Paulista - UNESP/Rio Claro \\ Programa de Pós-Graduação em Geociências e Meio Ambiente \\ robsonwillians@yahoo.com.br \\ Beatriz Lima de Paula \\ Universidade Estadual Paulista - UNESP/Rio Claro \\ Programa de Pós-Graduação em Geociências e Meio Ambiente
}

\footnotetext{
*Este artigo deve ser referido como segue:
}

Silva R. W. C., Paula B. L. 2009. Causa do aquecimento global: antropogênica versus natural. Terræ Didatica, 5(1):42-49<http:// www.ige.unicamp.br/ terraedidatica/>

\begin{abstract}
CAUSES OF GLOBAL WARMING: ANTHROPOGENIC VERSUS NATURAL. The controversies about the possible causes and effects of global warming are still little publicized, but can not be ignored. The predictions on the intensity of global warming and on its causes and consequences involve complex issues on which the scientific community itself has not yet reached a consensus. This paper discuss several pointof-views about global warming, not as to put the responsibily on human action during its brief history on Earth, nor the Earth's climate cycling, but to bring important information on the subject. This can help getting information and a mature opinion as based on scientific results. Increasing research on the several factors that cause fluctuations and climate change is needed, towards allowing comparisons between the characteristics of this global warming with the characteristics of the several earlier events of global warming.
\end{abstract}

KEYWORDS Global warming, greenhouse effect.

RESUMO As controvérsias sobre as possíveis causas e efeitos do aquecimento global ainda são pouco divulgadas, mas não podem ser ignoradas. As previsões sobre a intensidade do aquecimento global bem como sobre suas causas e consequências, envolvem questões complexas sobre as quais a própria comunidade científica ainda não chegou a um consenso. O objetivo deste trabalho é discutir os diversos pontos de vista e interesses de uma situação-problema, como é o aquecimento global, não responsabilizando simplesmente a ação humana durante sua breve história na Terra, nem a ciclicidade climática do planeta, mas trazer informações importantes sobre o tema, auxiliando na formação de uma opinião embasada em resultados científicos. Conclui-se que há necessidade de aumentar as pesquisas sobre os diversos fatores que causam as flutuações e mudanças climáticas, estabelecendo comparações das características do presente aquecimento em relação às características dos paleoaquecimentos.

PALAVRAS-CHAVE Aquecimento global, efeito estufa. 


\section{Introdução}

Um dos termos mais pesquisados em sites de busca e enciclopédias eletrônicas como Google ${ }^{\mathrm{TM}}$, Alta Vista ${ }^{\mathrm{TM}}$, Wikipédia e institutos de proteção ambiental como a Agência Norte-Americana de Proteção Ambiental (EPA), é o aquecimento global (Hitwise 2007).

O aquecimento global é um fenômeno climático de larga extensão, ou seja, um aumento da temperatura média superficial global, provocado por fatores internos e/ou externos. Fatores internos são complexos e estão associados a sistemas climáticos caóticos não lineares, isto é, inconstantes, devido a variáveis como a atividade solar, a composição físico-química atmosférica, o tectonismo e o vulcanismo. Fatores externos são antropogênicos e relacionados a emissões de gases-estufa por queima de combustíveis fósseis, principalmente carvão e derivados de petróleo, indústrias, refinarias, motores, queimadas etc.

O objetivo deste trabalho é fomentar a discussão dos diversos pontos de vista e interesses do aquecimento global, como situação-problema, não responsabilizando simplesmente a ação hu- mana durante sua breve história na Terra, nem a ciclicidade climática do planeta, mas trazer informações importantes sobre o tema, auxiliando na formação de uma opinião embasada em resultados científicos.

\section{Efeito estufa}

Os gases responsáveis pelo efeito estufa, como vapor de água, clorofluorcarbono (CFC), ozônio $\left(\mathrm{O}_{3}\right)$, metano $\left(\mathrm{CH}_{4}\right)$, óxido nitroso $\left(\mathrm{N}_{2} \mathrm{O}\right)$ e o dióxido de carbono $\left(\mathrm{CO}_{2}\right)$, absorvem uma parte da radiação infravermelha emitida pela superfície da Terra e irradiam, por sua vez, uma parte da energia de volta para a superfície (Fig.1). Como resultado, a superfície recebe quase o dobro de energia da atmosfera em comparação com a energia recebida do Sol, resultando em um aquecimento da superfície terrestre em torno de $30^{\circ} \mathrm{C}$. Sem esse aquecimento, a vida, como a conhecemos, não poderia existir.

O principal gás responsável pela geração do efeito estufa é o vapor de água troposférico. Sua concentração atmosférica provém unicamente de fontes naturais, tais como evapotranspiração e ati-

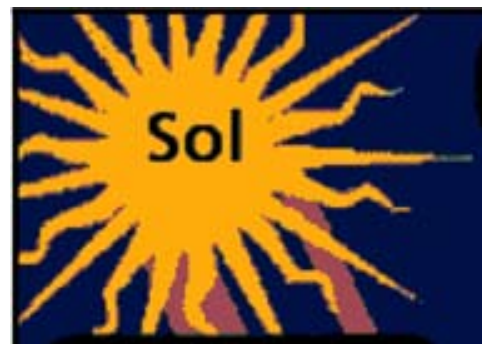

Aproximadamente metade da energia solar absorvida na superfície evapora água, adicionando o gás estufa mais importante à atmosfera. Quando esta água condensa na atmosfera, ela libera a energia que alimenta tempestades e produz chuvas e neves

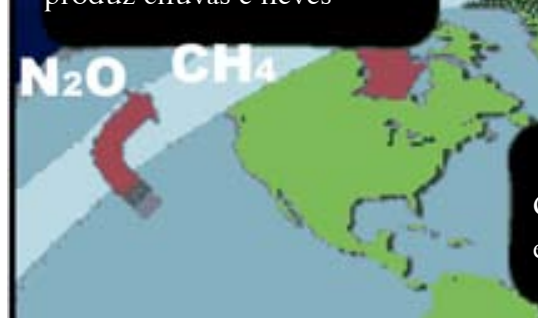

Figura 1 - Esquema do efeito estufa na Terra (Fonte: adaptado de Efeito Estufa, U.S. Global Change Research Program)

\section{O efeito estufa na Terra}

Apenas uma pequena porção da energia térmica emitida pela superfície passa através da atmosfera direto para o espaço. A maioria é absorvida por moléculas de gás estufa e contribuem para a energia irradiada voltar a aquecer a superfície e baixar a atmosfera, aumentando as concentrações de gases estufa que aumentam o aquecimento da superfície e diminuem a perda de energia para o espaço da energia solar que chega é refletida pela superfície e pela atmosfera.
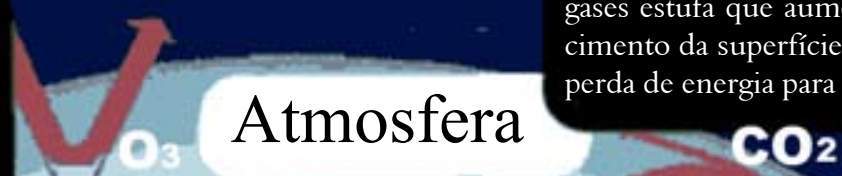

\section{Superfície}

A superfície resfria irradiando energia térmica para cima.

Quanto mais quente a superfície, maior a quantidade de energia térmica que é irradiado para cima
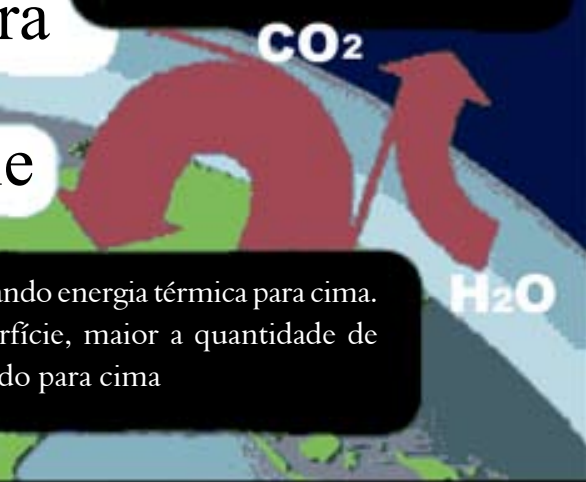
vidade vulcânica (IPCC 1990). Os principais gases antrópicos são o $\mathrm{CO}_{2}, \mathrm{o} \mathrm{CH}_{4}$ ( 20 vezes mais potente que o $\mathrm{CO}_{2}$ como gás-estufa), e o $\mathrm{N}_{2} \mathrm{O}$. O Painel Intergovernamental para as Mudanças Climáticas (IPCC), descreve no seu relatório de 2007 que a concentração atmosférica global de $\mathrm{CO}_{2}$ aumentou de 280 ppm em 1750 para 379 ppm em 2005, significando um aumento de $35,35 \%$. A concentração atmosférica global de $\mathrm{CH}_{4}$ aumentou de $715 \mathrm{ppb}$ em 1750 para 1732 ppb no início da década de 1990, e 1774 ppb em 2005, significando um aumento de $148 \%$, e a concentração atmosférica global de $\mathrm{N}_{2} \mathrm{O}$ aumentou de 270 ppb em 1750 para 319 ppb em 2005 , significando um aumento de 18,15\%.

Grande parte do aquecimento observado durante os últimos 50 anos se deve a um aumento nas concentrações de gases-estufa de origem antro- pogênica. Em um período de 100 anos houve um aumento médio da temperatura global dos continentes de $0,85^{\circ} \mathrm{C}$, da temperatura global do oceano de $0,55^{\circ} \mathrm{C}$ e da temperatura global da Terra de $0,7^{\circ} \mathrm{C}$ (Fig. 2) (IPCC 2007).

Modelos matemáticos climáticos projetam que as temperaturas globais de superfície provavelmente aumentarão no intervalo entre 1,1 e $6,4^{\circ} \mathrm{C}$, e o nível médio das águas do mar subirá entre 9 a $88 \mathrm{~cm}$ entre 1990 e 2100 (Fig. 3) (IPCC 2007). O aumento do nível do mar trará impactos ambientais e sócioeconômicos significativos: risco de submersão de ilhas planas (como o arquipelágo da Indonésia, que poderá perder até 2 mil de suas 17,5 mil ilhas), portos e terrenos agrícolas; salinização das águas potáveis superficiais e subterrâneas; mudanças em padrões de precipitação, resultando em enchentes

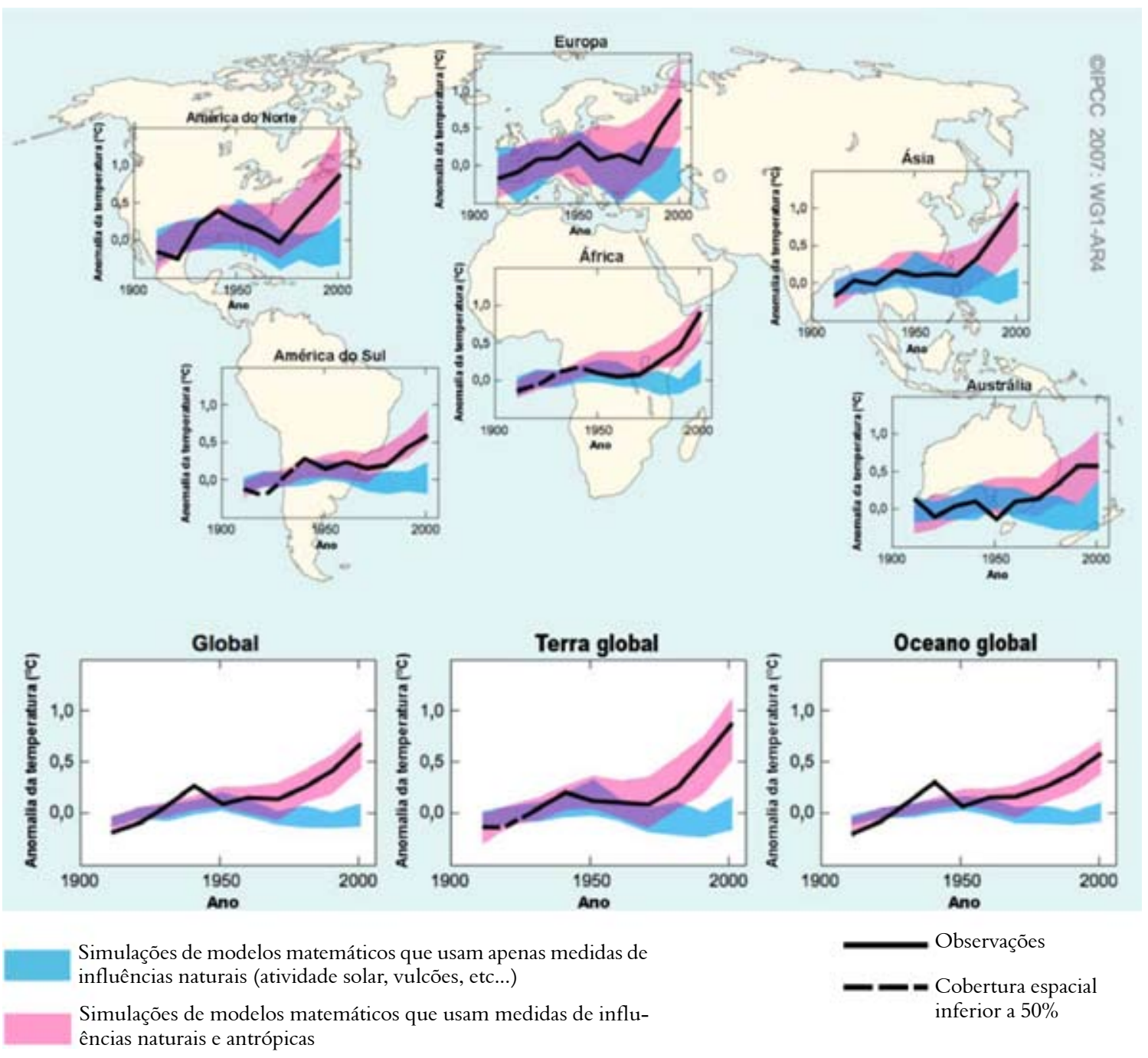

Figura 2 - Comparação das mudanças observadas na temperatura da superfície em escalas continental e global (Fonte: IPCC 2007) 
e secas, podendo acelerar o fenômeno de desertificação; poderá haver também um ligeiro aumento de amplitude do fenômeno El Niño, o qual acarreta estiagem na Amazônia (Lefale 2002).

As mudanças verificadas na figura 3 são relativas às médias correspondentes para o período de 1961 a 1990 . As curvas suavizadas representam valores médios decenais, enquanto os círculos indicam valores anuais. As áreas sombreadas são os intervalos estimados por meio de uma análise abrangente das incertezas conhecidas (a e b) e nas séries temporais (c).

Com base em 2,5 anos de levantamento de dados por meio de satélites com sensores gravimétricos, detectou-se que as geleiras da Groenlândia, a segunda maior fonte de água doce do planeta, estão derretendo cerca de $1,8 \mathrm{~mm}$ por ano, três vezes mais rápido do que foi observado nos últimos 5

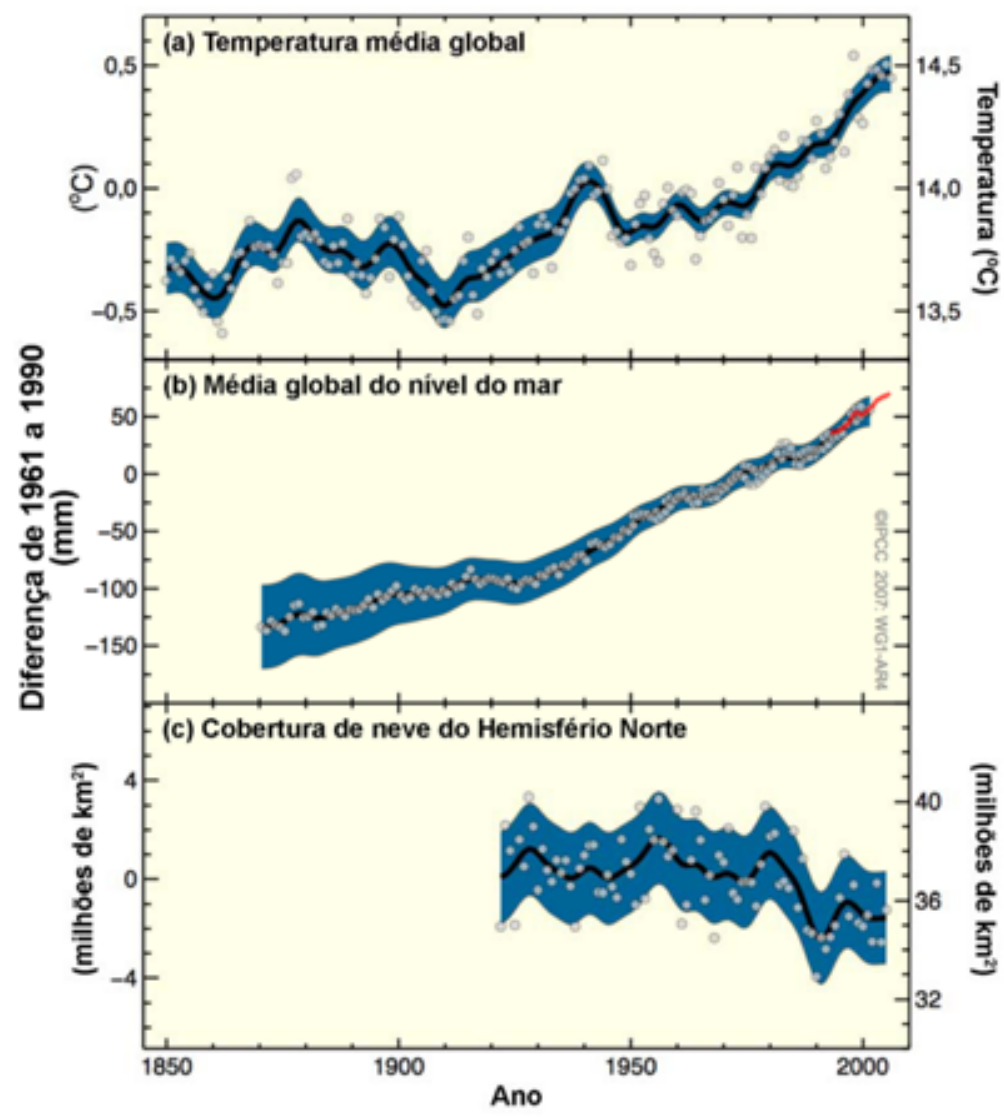

Figura 3 - Mudanças observadas na (a) temperatura média global da superfície, (b) média global da elevação do nível do mar a partir de dados de marégrafo (azul) e satélite (vermelho) e (c) cobertura de neve do Hemisfério Norte para março-abril (Fonte: IPCC 2007)

anos (Petit et al. 1999, Chen et al. 2006, Dowdeswell 2006). Pelas projeções de aquecimento médio global, até 2100 , grande parte do gelo da Groenlândia terá derretido, resultando em uma elevação do nível do mar de 3 a $4 \mathrm{~m}$ (Overpeck et al. 2006).

O derretimento dos lagos congelados da Sibéria Ocidental, congelados na última glaciação no final do Pleistoceno Superior, há 11.000 anos, e considerados como a maior turfeira do mundo, com cerca de $25 \%$ do $\mathrm{CH}_{4}$ do planeta, está auxiliando a liberação de $10 \mathrm{~g} \cdot \mathrm{m}^{-2} /$ dia de $\mathrm{CH}_{4}$ para atmosfera (Walter et al. 2006, Petit et al. 1999).

Desde sua origem, há aproximadamente 4,55 bilhões de anos, o planeta Terra está em constante desenvolvimento, tendo passado por inúmeras alterações climáticas. Algumas dessas mudanças foram tão drásticas que diversos organismos vivos não foram capazes de se adaptar e foram extintos, como mostram os abundantes registros fósseis. Nesse processo de desenvolvimento natural existem ciclos de aquecimento global devido à atuação combinada dos fatores internos: as massas continentais, por exemplo, em função do tectonismo de placas, estão em constante movimento, e as mudanças de latitude e longitude afetam o clima nas mesmas.

Durante 345 milhões de anos da Era Paleozóica (570 milhões a 225 milhões de anos atrás) a temperatura média da Terra era superior à atual, que é de $15^{\circ} \mathrm{C}$. Desde cerca de 300 milhões de anos atrás foram descobertas assembléias fossilíferas de vegetais representativos de climas quentes e úmidos em diversas partes da Terra (Suguio 2008). Durante cerca de 80 a $90 \%$ da Era Paleozóica as regiões polares da Terra não se apresentaram recobertas de geleiras, mas entre os períodos Siluriano-Ordoviciano (500 milhões a 430 milhões de anos) ocorreram glaciações não muito intensas. Além disso, entre os períodos Permiano e Carbonífero (345 milhões a 280 milhões de anos atrás) ocorreu uma glaciação 
mais intensa. Durante essas glaciações, as geleiras, especialmente as que recobriram grandes áreas do Supercontinente Gondwana, estenderam-se por até 10 milhões de quilômetros quadrados e as espessuras variaram de 2.000 a $3.000 \mathrm{~m}$. Evidências desses acontecimentos de glaciações permocarboníferas do Supercontinente Gondwana são representadas no Parque do Varvito de Itu. O varvito é uma rocha sedimentar depositada em fundo de lago formado por água de degelo acumulada em depressão do terreno.

Durante a Era Mesozóica, que durou cerca de 160 milhões de anos (225 milhões a 65 milhões de anos), a temperatura média da Terra atingiu 30 a $33^{\circ} \mathrm{C}$ e, mesmo nas regiões polares, as temperaturas eram variáveis entre 8 a $10^{\circ} \mathrm{C}$ (Suguio 2008). Houve um grande aquecimento global no final da Era Mesozóica durante o Cretáceo (entre 145 e 65 milhões de anos atrás). Neste período, os níveis de $\mathrm{CO}_{2}$ atingiram valores quatro vezes maiores que os níveis do final da Revolução Industrial, com temperaturas médias anuais superiores a $38^{\circ} \mathrm{C}$ nos trópicos e maiores do que $10^{\circ} \mathrm{C}$ nos pólos, e a insolação estava entre 3 e $6 \%$ superior a atual devido à menor concentração de material particulado na atmosfera, produzindo assim número menor de nuvens (Kump \& Pollard 2008).

No final do Cretáceo houve grande resfriamento no globo terrestre; uma das causas bem aceitas no meio científico foi o impacto de asteróide que atingiu a região de Yucatan no México, que teria originado espessa camada de poeira, impedindo a incidência dos raios solares na superfície terrestre, resultando em grande evento de extinção em massa de espécies vegetais e animais.

A Era Cenozóica, que perdura há 65 milhões de anos, exibia no início clima quente como nos primeiros tempos da Era Mesozóica. Porém no fim do Período Terciário (há 2 a 3 milhões de anos), iniciaram-se as glaciações quaternárias. As paleotemperaturas da época apresentaram mudanças variáveis, temporal e espacialmente, estabelecendo-se diferenças de menos de $1^{\circ} \mathrm{C}$ em 100 anos e mais de $10^{\circ} \mathrm{C}$ em centenas de milhares de anos nas temperaturas médias (Suguio 2008).

Nos últimos 6 mil anos a temperatura média subiu $2^{\circ}$ a $3^{\circ} \mathrm{C}$. Durante o último milênio houve grandes variações de temperatura (Fig. 4). Entre os séculos IX e XII houve o Período Quente Medieval, com temperaturas mais altas que as atuais, e a "Pequena Idade do Gelo", entre os séculos XVII e XIX, mais fria e da qual o aquecimento registrado no século XX (Fig. 5) parece não ser mais que uma recuperação (Briffa 2000, Jones et al. 2001, Mann et al. 2003). Como as medições diretas com termômetros tiveram início apenas no final do século XVIII, as épocas anteriores são estudadas com métodos indiretos - isótopos de oxigênio, pólens, anéis de crescimento de árvores, formações geológicas características, entre outros. Esses métodos proporcionam um quadro suficientemente preciso sobre o clima vigente em um dado período.

Houve ligeiro resfriamento no Hemisfério Norte de $0,2^{\circ} \mathrm{C}$ durante o último milênio (10001900), seguido de uma brusca elevação de $0,6^{\circ} \mathrm{C}$, no período 1900-2000, do qual resulta um gráfico cuja forma ficou conhecida como o "taco de hóquei" (Mann et al. 1998, 1999), e foi extensamente

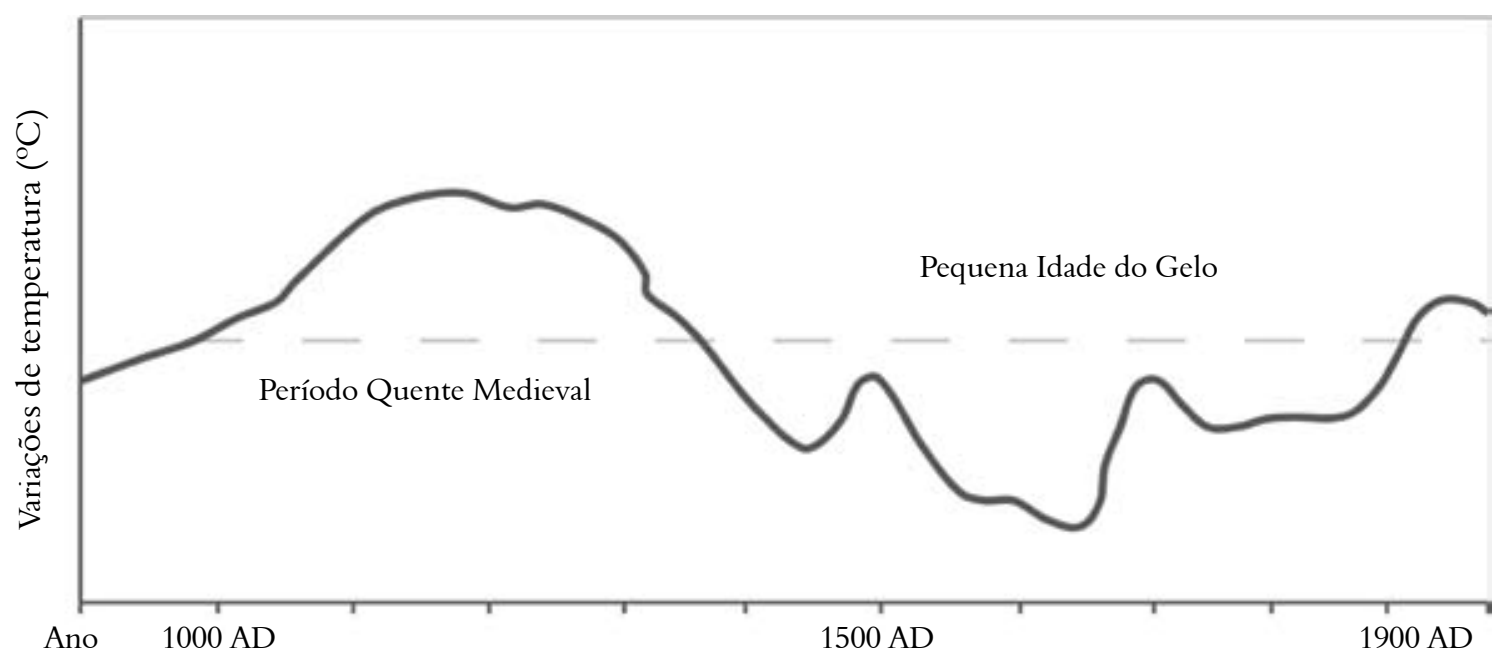

Figura 4 - Curva de variação de temperatura durante o último milênio (IPCC 1990) 


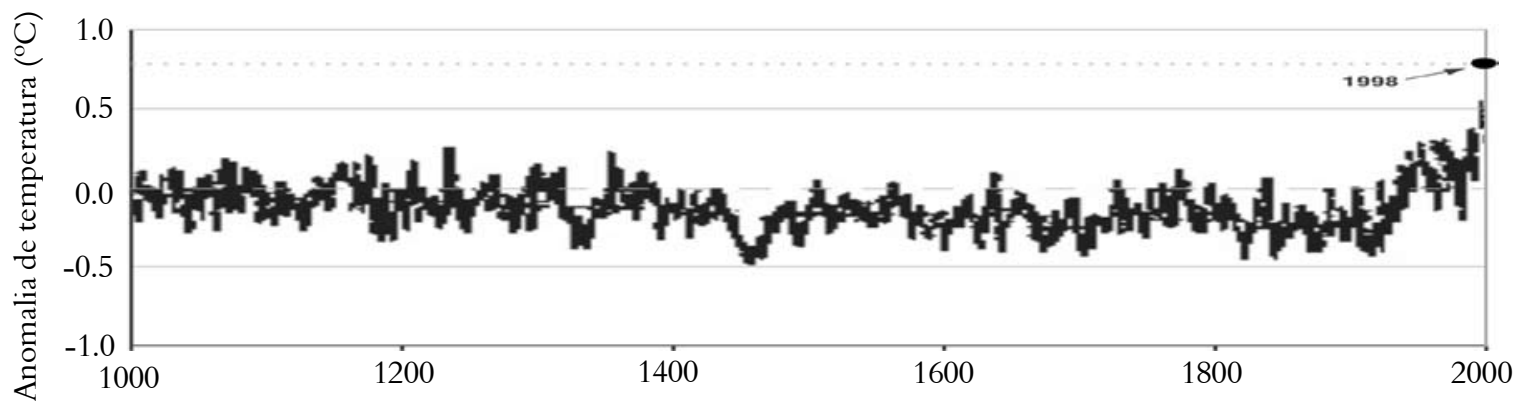

Figura 5 - Reconstrução das temperaturas no Hemisfério Norte ("taco de hóquei") (Mann et al. 1999)

alardeado pelo IPCC e a comunidade ambientalista como evidência cabal da ação humana no clima. Porém, como foi prontamente demonstrado, o gráfico foi simplesmente considerado por inúmeros cientistas como falso. O que também chamou a atenção foi o fato de que o gráfico eliminava sumariamente o Período Quente Medieval e a "Pequena Idade do Gelo".

Mcintyre \& Mckitrick (2003) e Wegman et al. (2006), analisaram os dados e a metodologia usados por Mann et al. (1999) e concluíram que os modelos matemáticos empregados apresentavam inúmeros erros, produzindo-se um gráfico em forma de "taco de hóquei", independentemente dos dados aplicados a eles.

Análises em registros de gelo da Antártica mostram cinco breves períodos interglaciais ocorridos desde 415 mil anos atrás até o presente (Fig. 6) (Salamatin et al. 1998; Petit et al. 1999). As amostras do gelo da Groenlândia revelam um Período Quente Minoano (1450-1300 a.C.), um Período Quente Romano (250-0 a.C.), o Período Quente Medieval (800-1100), a "Pequena Idade do Gelo" (1650-1850) e o Período Quente do Século XX (1900-2010) (Evans 2007).

$\mathrm{O}$ século $\mathrm{XX}$ foi quase tão quente como os séculos do Período Quente Medieval. O recente período quente 1976-2000 parece ter chegado ao fim; astrofísicos que estudam o comportamento das manchas solares prognosticam que os próximos 25-50 anos poderão compor um período frio semelhante ao Mínimo de Dalton, ocorrido entre as décadas de 1790 e 1820 (Evans 2007).

As evidências que vinculam as emissões de $\mathrm{CO}_{2}$ antropogênicas ao presente aquecimento se limitam a uma correlação entre concentrações de $\mathrm{CO}_{2}$ e temperaturas, que só se verifica no período 1976-2000. As tentativas de se elaborar uma teoria holística, pela qual o $\mathrm{CO}_{2}$ atmosférico controla o balanço de radiação da Terra e, portanto, determina as temperaturas médias globais, não foram bemsucedidas (Fig. 7).

A figura 7 mostra as variações naturais das temperaturas e concentrações de $\mathrm{CO}_{2}$ ao longo dos últimos 550 milhões de anos. Observa-se que as duas curvas são relativamente independentes, $\mathrm{o}$ que descaracteriza as teorias sobre o $\mathrm{CO}_{2}$ antropogênico. As mudanças climáticas são uma constante na história geológica da Terra.

\section{Conclusão}

Grande parte da comunidade científica acredita que o aumento da concentração de poluentes antropogênicos na atmosfera é a causa principal do efeito estufa, consequentemente do aquecimento global. Independente de sua causa, o efeito estufa antrópico ou a recuperação natural do clima após três séculos (séculos XVII a XIX) de baixas temperaturas durante o período da "Pequena Idade do Gelo" tem ocasionado efeitos devastadores nos ecossistemas.

De fato, têm sido detectadas inúmeras consequências do aquecimento global, como subidas do nível relativo do mar, atribuídas ao degelo como consequência do aumento de temperatura durante o século XX, mudança no padrão climático em âmbito regional, ocasionando mudanças em padrões de chuva, etc. Os impactos não são apenas ambientais, mas econômicos e sociais.

O planeta já sofreu, ao longo de sua existência de aproximadamente 4,55 bilhões de anos, processos de resfriamentos e aquecimentos extremos. Está comprovado que houve alternância de climas quentes e frios, sendo este um fenômeno corrente na história do planeta. Por isso, as evidências causais estão nas características do atual aquecimento em 


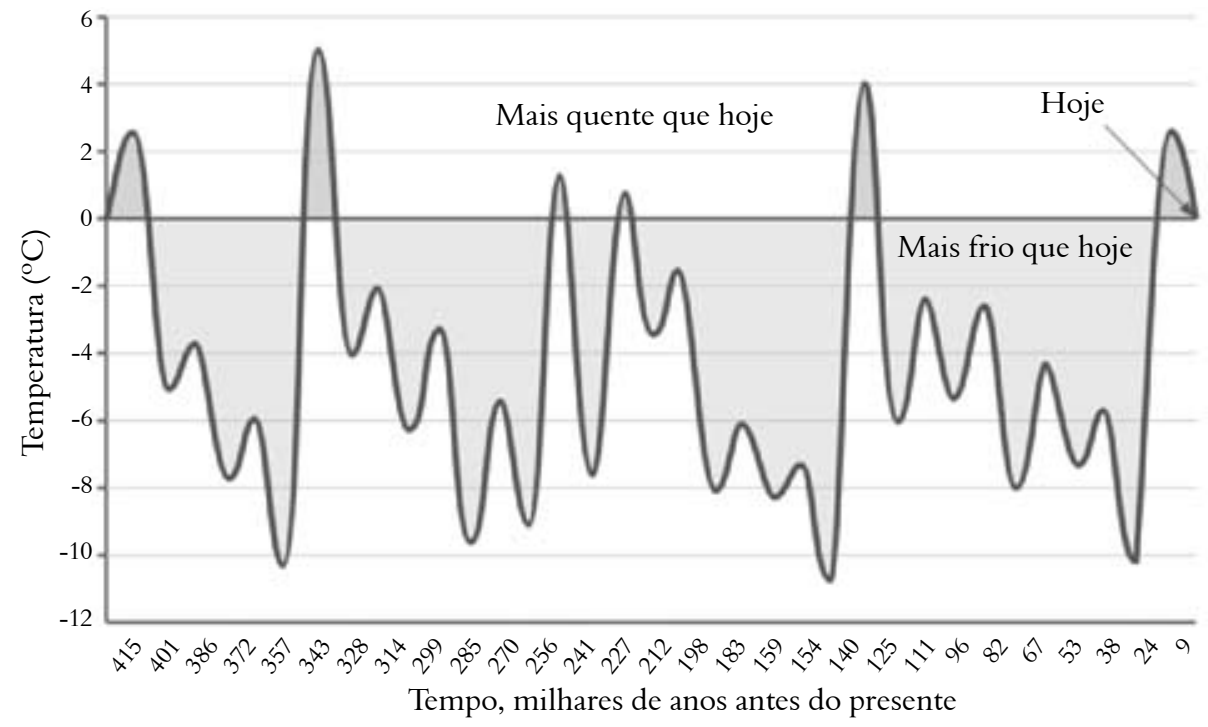

Figura 6 - Ciclos climáticos nos últimos 415.000 anos (Salamatin et al. 1998)

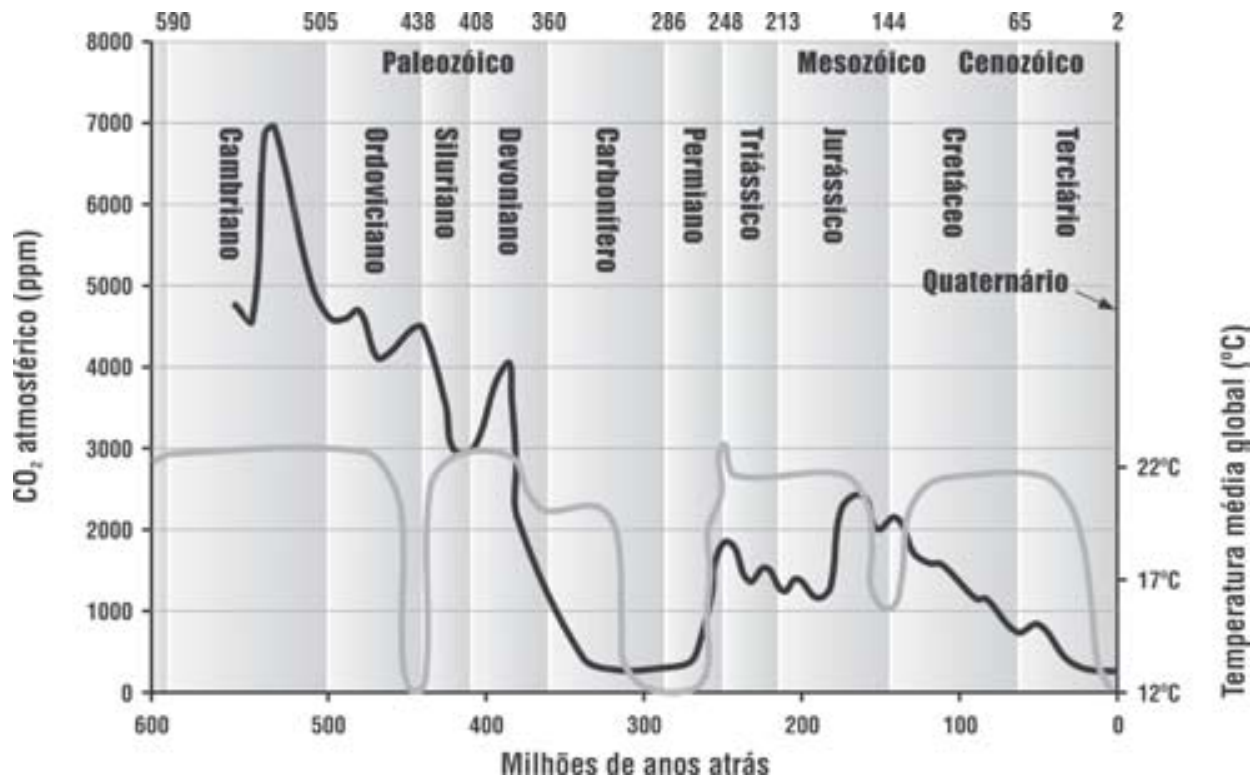

Figura 7 - Concentração de $\mathrm{CO}_{2}$ atmosférico durante as eras geológicas (Fonte: adaptado da Fundação Argentina de Ecologia Científica)

relação aos anteriores, como o percentual e o tempo de retroalimentação do vapor de água na atmosfera, a atividade solar, concentração na atmosfera de gases provenientes de desastres naturais - metano pelo degelo de áreas pantanosas, óxidos de nitrogênio e dióxido de carbono por erupções vulcânicas e queimadas.

As simulações climáticas referentes ao início do século passado (1900 a 1950) podem ser explicadas somente pelos fatores internos e naturais, mas o aquecimento ocorrido após a metade do século passado até o momento, para ser explicado, necessita dos fatores externos como as emissões de gases de origem antropogênica, responsáveis pelo efeito estufa. Essa explicação é devida principalmente ao tempo de permanência desses gases na atmosfera, em sua maioria acima de cem anos, e a velocidade do aumento da temperatura global nas últimas décadas. Os fatores externos estão sendo incorretamente incorporados aos modelos climáticos como, por exemplo, a retroalimentação do vapor de água na atmosfera, gerando assim resultados superesti- 
mados. Mas há um consenso entre os cientistas: a de que, se os modelos melhorassem, não alterariam a conclusão.

Certamente, quando as questões supracitadas puderem ser respondidas com precisão, tornar-se-á possível responder se o aquecimento global é de origem natural ou antropogênica, e prognosticar com maior certeza os climas do futuro durante o século XXI. Deste modo, deverão surgir possibilidades de se evitar mudanças ambientais, cujas consequências possam ser danosas ao ser humano, bem como a outros seres vivos.

Há necessidade de se pesquisar, ainda mais, os diversos fatores que causam as flutuações e mudanças climáticas. A verdadeira dimensão das causas que reconhecidamente interferem entre si continuará sendo objeto de muitos debates entre os cientistas, e de notável interesse pelo público em geral para o entendimento dos processos naturais e dos efeitos das ações antropogênicas e suas interações.

\section{Referências}

Briffa K.R. 2000. Annual climate variability in the Holocene: interpreting the message of ancient trees. Quaternary Science Reviews, 19(1):87-105.

Chen J.L., Wilson C.R., Tapley B.D. 2006. Satellite gravity measurements confirm accelerated melting of Greenland ice sheet. Science, 313(5795):19581960.

Dowdeswell J.A. 2006. The Greenland Ice Sheet and global sea-level rise. Science, 311(5763):963964.

Evans R. Nine facts about climate change. URL: http:// www.lavoisier.com.au/articles/greenhousescience/climate-change/longversionfinal.pdf. Acesso 30.09.2007.

Fundação Argentina de Ecologia Científica. A fraude do aquecimento global. URL: http://www. mitosyfraudes.org. Acesso 30.09.2007.

Hitwise. Online Searches for "Global Warming" Heating Up In February. URL: http://www.hitwise.com/ press-center/hitwiseHS2004/globalwarming.php. Acesso 30.09.2007.

Kump L.R., Pollard D. 2008. Amplification of Cretaceous warmth by biological cloud feedbacks. Science, 320(5873): 195.

IPCC. Intergovernmental Panel on Climate Change. eds. 1990. "Greenhouse gases and aerosols", in climate change: The IPCC scientific assessment - report of IPCC working group. Cambridge: Cambridge Univ. Press. 364 p.

IPCC. Intergovernmental Panel on Climate Change. eds. 2007. Climate change 2007: The physical science basis. Contribution of working group I to the fourth assessment report of the Intergovernmental Panel on Climate Change. Cambridge: Cambridge Univ. Press. 996p.

Jones P.D., Osborn T.J., Briffa K.R. 2001. The Evolution of Climate Over the Last Millennium. Science, 292(5517):662-667.

Lefale P.F. 2002. The vulnerability of Pacific Islands to climate change. Pacific Ecologist, 1:19-22.

Mann M.E., Bradley R.S., Hughes M.K. 1998. Global-Scale temperature patterns and climate forcing over the past six centuries. Nature, 392:779-787.

Mann M.E., Bradley R.S., Hughes M.K. 1999. Northern hemisphere temperatures during the past millennium: Inferences, uncertainties, and limitations. Geophys. Research Letters, 26:759762.

Mann M.E., Jones P.D. 2003. Global surface temperatures over the past two millennia. Geophys. Research Letters, 30(15):1820.

Mcintyre S., Mckitrick R. 2003. Corrections to the Mann et. al. (1998) proxy data base and northern hemispheric average temperature series. Energy $\mathcal{E}$ environment, 14(6):751-771.

OverpeckJ.T., Otto-Bliesner B.L., Miller G.H., Muhs D.R., Alley R.B., Kiehl J.T. 2006. Paleoclimatic evidence for future ice-sheet instability and rapid sea-level rise. Science, 311(5768):1747-1750.

Petit J.R. et al. 1999. Climate and atmospheric history of the past 420,000 years from the Vostok ice core, Antarctica. Nature, 399:429-436.

Salamatin A.N., Lipenkov V.Y., Barkov N.I., Jouzel J., Petit J.R., Raynaud D. 1998. Ice core age dating and paleothermometer calibration based on isotope and temperature profiles from deep boreholes at Vostok Station (East Antarctica). J. Geophys. Res., 103(8):8963-8977.

Suguio K. 2008. Mudanças Ambientais da Terra. São Paulo: Inst. Geológico. 336 p.

U.S. Global Change Research Program. O que é efeito estufa?. URL: http://ambiente.hsw.uol.com.br/ questao746.htm. Acesso 30.09.2007.

Walter K.M., Zimov S.A., Chanton J.P., Verbyla D., Chapin III F.S. 2006. Methane bubbling from Siberian thaw lakes as a positive feedback to climate warming. Nature, 443:71-75.

Wegman E.J., Scott D.W., Said Y.H. 2006. Ad hoc committee report on the 'hockey stick' global climate reconstruction. Wegman Report. 91 p. 